\title{
AS DUAS CULTURAS REVISITADAS - DE NOVO
}

\author{
Saulo Cunha de Serpa Brandão*
}

\begin{abstract}
RESUMO: Este trabalho tem como propósito clarear o estado em que se encontra o relacionamento entre as ciências ditas duras (física, química, biologia), as artes e a literatura, ou melhor, entre cientistas e artistas. Aponta a inexistência de separações no passado e mostra alguns fatores que levaram ao apartamento que existe hoje.
\end{abstract}

Palavras-chave: C. P. Snow, Swift, Divisão das Áreas, Cientistas e Artista, Financiamento de Pesquisa.

\section{Avant-propos}

Este ensaio que apresentamos a seguir foi já publicado em 2002, na revista Letras \& Letras (UFU). Ele aparece publicado agora, com pequenas alterações, e acrescentado deste prólogo, por razões muito especiais para quem se preocupa com as relações entre Artes (Literatura, principalmente) e Ciência. Um primeiro motivo e talvez o mais importante, foi a imersão na realidade que tive durante 4 anos em que fui pró-reitor de pesquisa e pós-graduação de minha instituição. Esta passagem pela administração de uma IFES me fez ver o quanto eu tinha sido naïve quando publiquei este ensaio pela primeira vez. Naquela época, eu cheguei a ter uma visão otimista das relações entre as áreas. Tanto é assim que encerrei o texto prevendo um futuro pacífico entre cientistas e humanistas (aqui incluído as artes, literatura).

Mas com a experiência que tive em reuniões em que se definiam os valores a serem aportados para cada área, me sinto na obrigação de republicar este texto. Ele é muito atual, e decidi escrever esta nota prévia para alertar meus leitores que, talvez, tenham a mesma visão otimista que eu tive em 2002. Mas não mais: assisti agência de fomento criar escala de peso para o investimento em cada área

\footnotetext{
*Universidade Federal do Piauí. Imeio: scsbrandao@gmail.com.

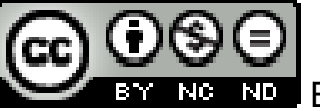

Texto Digital, Florianópolis, v. 9, n. 2, p. 230-258, jul./dez 2013. ANO. ISSNe: 1807-9288 
e vi as humanidades e artes serem colocadas na última colocação e com fração de 1 ponto de peso. Esta mesma tabela serviria para distribuição de bolsas.

Assisti, assim como todos vocês, leitores, a presidente da república criar o Programa Ciência sem Fronteiras e determinar publicamente que seu ministro da educação não incluísse as áreas de Humanidades no Programa. Mesmo este retrucando, publicamente, que tanto ele como a presidente eram economistas, ao que ela respondeu que eles conheciam bem a área. Deixando uma mensagem implícita que por serem economistas eles sabiam que a área não deveria ser incluída.

A paz entre as áreas não vai poder acontecer (pelo menos para nós literatos) enquanto os números declarados pela CAPES em seu Geocapes (<http://geocapes.capes.gov.br/geocapesds/\#>) apontar o número baixíssimo de bolsas para a área de Letras. As humanidades, nesses gráficos, aparece com um número alto de bolsa, mas há de se levar em consideração o número de PPGs da área (nas Humanas existem 792 cursos e tem, aproximadamente, 25\% menos bolsas que Ciências Exatas e da Terra, sendo que nesta existem 481 cursos). A fonte destes números é também no sítio da CAPES (<http://conteudoweb.capes.gov.br/conteudoweb/ProjetoRelacao CursosServlet?acao=pesquisarGrandeArea>)

O leitor mais curioso poderá constatar outras discriminações apoiada pelo governo brasileiro, que é nosso maior financiador de pesquisas e qualificação de pesquisadores. Não vou considerar aqui o $\mathrm{CNPq}$, pois os dados deste são confusos para mim. E para se ter um panorama mais completo, poderíamos analisar a política para patentes. Mas esta tarefa deixo para algum outro ensaio sobre 0 assunto.

Por essas razões, decidi publicar este texto de novo, agora em uma revista digital que tem mais penetração e tem alcance internacional. 
No mais, desejo uma boa leitura, e que esta incentive meu leitor a refletir sobre o papel de literatos, linguistas e artistas na academia e na sociedade. Eu não vejo meio para diminuir o abismo que existe entre as áreas, a não ser sendo subversivo e encontrar caminhos criativos para fazer a pesquisa que queremos fazer.

\section{O Ensaio}

Os que habitamos o mundo neste começo de século $X X I$, graças a um aprendizado imposto aos nossos ancestrais nos últimos três ou quatro séculos, desenvolvemos uma maneira atrofiada de ver o mundo. Acreditando na crença introduzida em nosso meio, sustentando que conhecer as partes é conhecer o todo e para conhecer o todo temos que começar pelas partes, criamos uma visão compartimentada do mundo. Para o homem comum funciona, ainda, a metáfora do relógio: no universo, as partes se complementam para constituir uma unidade formal e funcionalmente perfeita. É quase impossível convencer uma pessoa comum de que o mundo deve ser visto e compreendido como um todo inseparável e indivisível e que as ações e reações nem sempre seguem, obrigatoriamente, esta ordem. Mas não foi sempre assim.

Os indivíduos mais curiosos e esclarecidos conhecem uma época em que os compartimentos não faziam parte de nossa lógica. Pensadores como Aristóteles e Platão, para citar apenas dois dos mais conhecidos, se preocupavam com todos os aspectos do mundo em que viviam. Tratavam da ética, da estética, da retórica, das artes, dos fenômenos físicos, da matemática. Obviamente, esses 
pensadores ${ }^{2}$ podiam ser mais argutos para determinadas observações do que para outras, mas não havia discriminação do objeto sobre o qual eles deviam se debruçar e especular ou como a investigação seria feita. Com esse espírito eles construíram obras notáveis que servem de referência para a humanidade até os nossos dias e continuarão a influenciar muitas outras gerações.

A perspectiva de mundo na Antiguidade Clássica era, sem sombra de dúvida, panorâmica - aplicamos este termo descartando qualquer traço semântico que indique pouca profundidade. Se usarmos o cinema para melhor perceber as diferenças de visão, podemos pensar no espectro de vista do homem clássico como um Cinerama com uma tela de $360^{\circ}$, enquanto a do homem atual, quando muito bem informado, não chega a ser a de um Super 8, Reversível, P/B. Mas, entre o mundo clássico e a contemporaneidade, muita coisa aconteceu e o resultado é essa miopia epidêmica em que vivemos. Durante toda a Idade Média, o homem continuou a se preocupar com aspectos diversos do mundo em que vivia - menos na Baixa Idade Média e mais na Alta Idade Média. Sabemos que homens como Santo Agostinho, por exemplo, embora fosse um teólogo nato em suas especulações, tratava de aspectos da percepção da realidade que, hoje, poderiam ser categorizados como estudos da física condensada, da teoria do conhecimento, da psicologia cognitiva. Mas que, para ele, eram apenas especulações sobre a interpretação das Escrituras. Mais tarde a física e a história moderna atribuíram ao pensador católico o crédito pela introdução do conceito de "tempo histórico" no pensamento ocidental. Tempo é uma variável/dimensão fundamental da física moderna, como também o era para a física clássica newtoniana.

\footnotetext{
${ }^{2}$ Neste texto, muitas vezes usaremos os substantivos pensadores, pesquisadores, estudiosos para nos referirmos ao intelectual que habitava nosso mundo desde a Antiguidade Clássica até o início do século XVIII, mas cabe lembrar que esses seres eram também: poetas, ficcionistas, pintores, escultores, retóricos, arquitetos, engenheiros, ou seja, intelectuais completos. Pessoas que, além de filosofarem profundamente sobre temas primeiros, eram engenhosas e habilidosas tanto no trato das palavras, como no das coisas ou das ideias.
}

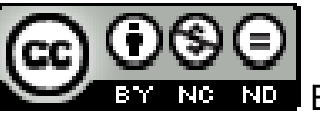

Texto Digital, Florianópolis, v. 9, n. 2, p. 230-258, jul./dez 2013. ANO. ISSNe: 1807-9288 
Na virada do século XVI para o XVII, vamos encontrar os últimos pensadores que se ocuparam, sistematicamente, de estudos científicos e humanísticos como uma unidade completa. A figura do intelectual absoluto encontra em Leonardo da Vinci $^{3}$ seu melhor e mais característico exemplar. Esgotava-se com ele uma tradição imensamente profícua para ceder lugar à prática tacanha de separar áreas de conhecimento e ceder abismos à ignorância.

O fato é que, desde o início do século XVII, uma nova lógica começava a impregnar os grandes pensadores e ideólogos. Não é fácil, quiçá impossível, determinar o momento histórico em que a prática da especialização começou a granjear a simpatia dos intelectuais no ocidente, tampouco sabemos a razão que levou os estudiosos a tomarem esse caminho. Como para os períodos da história, é muito difícil precisar o momento da mudança, mas nada nos impede de especular. Os motivos que levaram os estudiosos ao câmbio das práticas no meio científico também são obscuros.

Exercitando um pouco nosso conhecimento de história, vamos perceber que 0 início do século XVII foi o marco temporal para a observação dos movimentos sociais que, acreditamos, resultaram da ebulição cultural que ocorreu nos séculos $\mathrm{XV}$ e XVI. Falamos de fatos históricos marcantes, como o ciclo das grandes navegações - que andou sempre de mãos dadas com a astronomia, estudo das correntes e dos ventos, técnicas de construção de naus, navegação, geografia; o começo dos estudos do cilindro a vapor - estes, mais tarde, resultariam em um

\footnotetext{
${ }^{3}$ O leitor mais curioso, ou mais ilustrado, encontrará, com certeza, pensadores posteriores a Leonardo da Vinci que continuavam se interessando por diversas áreas do conhecimento (Francis Bacon e Goethe são exemplos), mas, há de convir, que era, desde então, uma prática em desuso. Isaac Newton, embora seja conhecido por sua arrogância científica, declarou, em diversas oportunidades, seu aborrecimento com a ciência, chegando, inclusive, a publicar um livro sobre as profecias de Daniel e o apocalipse de São João (Observations of the Prophesies of Daniel and The Apocalypse of St. John (Printland Books, New York, 1998 [1733]) [Observações sobe as Profecias de Daniel e o Apocalipse de São João] num período em que ele estava completamente desencantado com a ciência e os cientistas. Foi grande amigo do filósofo John Locke e chegou a tecer especulações filosóficas com ele. Estas especulações sobre filosofia e teologia não eram vistas por ele como parte de suas preocupações profissionais. Os seus biógrafos preferem defender que teologia e filosofia eram parte do lúdico para ele. Uma espécie de compensação pelo cansaço que a ciência Ihe trouxe. Mesmo Einstein, já em no século XX, cultivava o hábito de escrever sobre artes, especialmente a música e era um grande filósofo.
} 
forte vetor para a grande Revolução Industrial - que iniciou e depois fomentou os estudos da termodinâmica, da resistência dos metais, da cinemática, da mecânica dos movimentos e dos atritos etc. Na área de interesse do que, hoje, chamamos ciências humanas, começávamos a ver o fim do feudalismo, germinação do mercantilismo e a consequente aparição de uma burguesia citadina. Estes fatos, em nossa compreensão, seriam os maiores empuxes no sentido da cientificidade e especialização em nossa cultura.

Essa paranoia por especialização terminou por concentrar todo o conhecimento e o conhecimento do todo, nas mãos daqueles que podiam manipular os caminhos das pesquisas. À medida que os pesquisadores não podem ampliar o foco de visão deles e perceber com largueza os vários aspectos do mundo que os cerca e não podem relacionar os seus objetos de estudo com todas as outras formas de conhecimento, torna-os, junto com suas pesquisas, joguetes nas mãos daqueles que os financiam e, estes sim, sabem exatamente como relacionar os trabalhos com outros para, finalmente, cumprirem os destinos que lhes estavam traçados com muita antecedência; só que os criadores/pesquisadores não sabiam. É assim que inocentes experimentos destinados ao uso pacífico em áreas como a medicina, por exemplo, transformam-se em partes de um projeto maior, com fins bélicos, industriais ou, puramente, logísticos (e.g. lasers criados para uso em microcirurgia transformam-se em miras para armas modernas ou ultrassons que terminaram utilizados como auxílio para navegação de naves bélicas ou, ainda, meios de comunicação muito rápidos, como a Internet, que foi criada dentro de muros de universidades, com o fim principal de agilizar a interação entre cientistas, hoje são utilizados para movimentar fundos que, de uma hora para outra, com um clique de mouse, pode levar nações pobres, com milhões de habitantes, à falência).

Ligando as pontas que deixamos soltas, observem a lógica que domina o financiamento da pesquisa: na Era Clássica, os pensadores eram, de uma forma geral, sustentados por senhores bem posicionados social e financeiramente. Tinham obrigações (nenhum mecenas doa dinheiro desinteressadamente), 
ensinavam os filhos desses senhores, compunham elegias sobre temas que interessavam aos seus protetores, escreviam discursos políticos ou epopeias enaltecendo heróis, nem sempre tão heroicos. No medievo, a coisa não mudou muito. Continuavam, os pensadores, a serem financiados por alguém ou alguma instituição - a Igreja Católica cumpriu um importante papel no mundo do mecenato nesse período, muitos estudiosos eram padres, monges, cardeais. Embora a vida eclesiástica fosse uma opção de ricos, encontramos muitos estudiosos pobres que conseguiram, por vias transversas, adentrar a lgreja a ter seus estudos financiados por esta. Com a Renascença ${ }^{4}$ e a posterior entrada na Era Moderna, as coisas mudam de perfil. Uma ideologia mais mercantilista se instala no âmago da sociedade e faz com que os fins comecem a ser questionados e, com isso, os meios ganham novo formato e uma diferente escala de valores para avaliá-los. O dinheiro migrava de mãos; saindo de umas que diamantizavam o ócio e faziam fortunas graças, apenas, ao berço em que nasceram e chegando a outras que labutavam, se arriscavam e morriam para juntar o que possuíam. Neste cenário, o financiador passou a questionar quais benefícios teria com os estudos a serem fomentados. Eles tinham de vislumbrar as melhorias que os adventos da pesquisa trariam para seu meio de produção ou qual conhecimento extra ele teria sobre a natureza do objeto com o qual ele lidava para ganhar a vida. Ora, cada dia ficava mais difícil conseguir financiamento; as verbas iam para projetos que trouxessem melhorias práticas, que pudessem gerar lucros rapidamente - o menor tempo para a conclusão da pesquisa virou uma commodity muito valiosa. Quanto menos tempo fosse preciso para concluir o experimento, menos oneroso ele ficava, mais rapidamente poderia entrar na cadeia de produção, retornando os investimentos e gerando mais lucros. Diante dessa lógica cruel, é natural que o estudioso se debruçasse mais intensamente sobre a estreita faixa de interesse na qual se coloca seu objeto e a abordagem escolhida, colocando de lado valores como beleza e ética. Preocupações desta natureza viram apêndices descartáveis; cada dia, mais a pesquisa se concentra

\footnotetext{
${ }^{4}$ Dentre alguns mecenas que podem ser citados na Renascença, destacam-se Lorenzo de Médici, Elizabeth I (Tudor). Ele deu continuidade à tradição patronal da família, que era uma das mais poderosas da Europa, e ela foi responsável por um período áureo para as artes e ciências na Inglaterra, hoje denominada de Era Elisabetana.
}

Texto Digital, Florianópolis, v. 9, n. 2, p. 230-258, jul./dez 2013. ANO. ISSNe: 1807-9288 
em um espectro mais acanhado - o que os cientistas chamam verticalização da pesquisa - e, cada vez mais, o sujeito vai empobrecendo seu espírito até o dia em que ele se torna, apenas, um aspecto descartável de sua própria pesquisa.

É dentro desse panorama que começa a divisão das áreas de conhecimento. E todo projeto que não entre imediatamente em um ciclo utilitário esta fadado a não receber financiamento - desce na escala de importância - e aqueles que se dedicam a essas áreas são relegados a pesquisadores de segunda categoria, destinados a viver em limbos acadêmicos rodeados de ideias brilhantes e incompreendidas. Esse foi o processo que, acreditamos, levou o homem moderno à situação de degradado e cego.

Cederemos algum espaço, agora, para Jonathan Swift. O ficcionista irlandês, com todo sarcasmo que lhe é peculiar, fez um retrato muito curioso da relação entre os homens da ciência e as fontes de financiamento para pesquisa, em seu mais famoso livro: Gulliver's trave ${ }^{F}$ (As viagens de Gulliver). Como é do conhecimento da maioria, As viagens... é dividido em quatro aventuras vividas por Gulliver, cirurgião e navegador, por terras remotas. São as seguintes as partes do livro: A Voyage to Lilliput (Uma viagem para Lilliput); A Voyage to Brobdingnag (Uma viagem para Brobdingnag); A Voyage to Laputa, Balnibarbi, Glubbdubdrib, Luggnagg, and Japan (Uma viagem para Laputa, Balnibardi, Glubbdubfrib, Lluggnagg e Japã); e, A Voyage to the country of the houyhnhnms (Uma viagem para o país dos houyhnhnm). Não desfazendo das outras três partes do livro, muitíssimo pelo contrário, comentaremos as observações de Gulliver quando este se encontrava em Laputa, primeira parada da terceira viagem e algumas das visitas subsequentes. Em realidade, esta parte do livro é considerada pelos estudiosos da obra de Swift como a mais desajeitada e deselegante de toda sua profícua produção. Mas, por uma dessas estranhas coincidências (?!), é a parte que parece talhada para apresentar o como e o porquê de um intelectual argucioso e capaz de finas sátiras, como Swift, tornar-se sarcástico, jocoso,

\footnotetext{
${ }^{5}$ Landa, Louis A., Gulliver's travels and other writings by Jonathan Swift, The Riverside Press: Boston, 1960. Todas as citações sobre As viagens ... serão retiradas dessa publicação.
} 
beirando a descortesia. Tão desalinhada é essa parte do texto, que muitos editores suprimiram-na em suas publicações. Ian Johnston comenta que

Of the four parts of Gulliver's Travels, the third, the A Voyage to Laputa, is for many the least satisfying and the least understood. The conventional critical take on Part Three is that the entire series of episodes is fundamentally pointless and artless in comparison.(1996, $\mathrm{s} / \mathrm{p})^{6}$

O fio que passa despercebido para a maioria dos críticos é que a própria maneira de escrever adotada pelo irlandês é, também, uma sátira refinada. Para uma pessoa que escreve com a elegância de Swift, escrever algumas dezenas de páginas que são apontadas pelos seus críticos como da mais pura incongruência, não deve ter sido tarefa fácil. Ele não viveu para ver editores apressados ceifarem justamente essa parte de sua obra.

O mistério começa a ser revelado se atentarmos para o nome da Parte III: A Voyage to Laputa... (Uma viagem para Laputa...). Para os falantes de português ou espanhol, é fácil perceber que uma das possibilidades de leitura do título pode ser algo como: viagem para a puta ou visita à puta. Essa possibilidade de leitura já é muitíssima explorada por pesquisadores de todos os lugares e de cepas variadas. Em várias passagens do livro Gulliver's travels: $A$ case study in contemporary criticism (Christopher , 1995) encontramos pesquisadores relacionando Laputa com a puta, em abordagens diversas como a feminista, a psicanalítica ou as desconstrutivistas. Acreditamos que não existe qualquer coincidência na escolha do título; Laputa é a puta. A característica da profissão de prostituta que mais causa estranheza é o fato delas venderem seus corpos, ou seja, ceder seus favores sexuais, em troca de dinheiro, fazer de seu sexo mercadoria. O leitor de A Voyage to Laputa... encontrará, sistematicamente, a menção de trocas com envolvimentos pecuniários - voltaremos a isso mais tarde.

\footnotetext{
${ }^{6}$ [Das quatro partes das Viagens de Guliver, a terceira, A viagem para Laputa é, para muitos, a menos satisfatória e menos entendida. A crítica convencional relativa à Parte Três é que toda a série de episódios é, fundamentalmente, sem sentido e não-artística quando comparada com as outras.] Tradução livre nossa.
} 
A deselegância, constatada por toda crítica especializada, na escrita de Swift nessa passagem é o que nos move agora.

Sabe-se que o ficcionista era contumaz leitor de textos científicos e especialmente aqueles publicados pela Sociedade Real de Ciência e que a maior parte dos experimentos descritos na Parte III, de fato, existiram e foram descritos nas publicações da Sociedade. Johnston nos ensina que

Most of the ideas he presents are based on real experiments reported in the literature of his day - and particularly on reports published in the Philosophical Transactions of the Royal Society during the last third of the 17th century and the first quarter of the 18th up to and including material published in 1726 - the year Swift composed Part III. (1996, $\mathrm{s} / \mathrm{p})^{7}$

O crítico canadense conseguiu rastrear as fontes reais de cada uma das experiências relatadas pelo comandante Gulliver na ficção, obviamente, aqui mais coloridas e ridicularizadas, mas não percebeu que o desalinho e a incoerência da escrita do irlandês eram, também, fortes críticas à maneira desajeitada e truncada dos cientistas escreverem seus relatórios. Não concebemos uma pessoa que escreve elegantemente, em um dado momento, produza um escrito sofrível. Especialmente se considerarmos que: Gulliver's... foi publicado em 1726; Swift viveu até 1745; é larga a produção do escritor entre a publicação de Gulliver's... e sua morte; Swift escreveu, em 1731, Verses on the death of Dr. Swift - uma elegia a sua pessoa (publicado anonimamente); e, finalmente, escreve seu próprio epitáfio. Pode-se concluir, com essas informações, que era extremo o cuidado que Swift tinha com a sua imagem pública. Ele escreve uma elegia a sua morte temendo que algum poeta menor tentasse a empreitada e produzisse um poema inferior. Ele escreveu seu próprio epitáfio temendo que algum jornalista apressado escolhesse qualidades de sua pessoa, Swift, que não correspondessem àquelas que ele mais prezava, como o espírito de liberdade.

\footnotetext{
${ }^{7}$ [A maior parte das idéias que ele apresenta são baseadas em experiências reais reportadas na literatura de seus dias - e particularmente em relatórios publicados em Philosophical Transactions of the Royal Society durante o último terço do século XVII e o primeiro quarto do século XVIII até e inclusive o material publicado em 1726 - o ano em que Swift publicou a Parte III.] Tradução livre nossa.
} 
A Parte III é uma sátira desvelada. Veremos a seguir que, em todo o episódio, Gulliver estará se relacionando com cidadãos extremamente versados em ciência, geometria e música. As elites das sociedades visitadas são cientistas que performavam as mais esdrúxulas experiências imaginadas. Em contraponto, o navegador conhece umas poucas pessoas esclarecidas e equilibradas que são ridicularizadas pelos cientistas por causa de seus pensamentos retrógrados.

Cada leitura que fazemos de A voyage to Laputa... mais certos estamos de que ela é sarcástica em relação ao mundo da ciência. O nosso intuito neste trabalho não é analisar as obras de Swift, mas é pertinente demonstrar como o escritor percebia e apontava a virada para a ciência que ocorria em seus dias. Vejamos rapidamente alguns dados que sustentam nossa crença.

Em Laputa, todas as coisas têm forma de instrumento musical, notas musicais ou figuras geométricas. Para a sociedade culta do século XVIII, época em que Swift estava escrevendo Gulliver's..., essas eram as formas mais perfeitas e universais que existiam. Para aqueles que viviam então, tudo podia estar errado, menos as figuras geométricas e a música. Dizia-se que estas formas, mesmo quando feias, eram bonitas e um famoso cientista da época, Christiaan Huygens, afirmava que

No matter how inhabitants of other planets might differ from man in no other ways, they must agree in music and geometry, since [music and geometry] are everywhere immutably the same, and always will be so. (Apud Johnston, 1996, s/p) ${ }^{8}$

Esse tipo de raciocínio é um dos procedimentos nefastos que nos deixam cegos. A classe dominante pensa de uma forma e, por ter uma postura sobranceira, generaliza o sua perspectiva de mundo como sendo o ponto de vista de toda sociedade. A partir daí, passa a tomar decisões e determinar padrões que só têm alguma lógica se observados usando a mesma lente que eles usam e isto não é possível de ser feito por todos os partícipes do grupo social. Aqueles que

\footnotetext{
${ }^{8}$ [Não interessa como habitantes de outros planetas possam diferir do homem em outras coisas, eles devem concordar em música e geometria, uma vez que [música e geometria] são imutavelmente iguais e sempre serão.] Tradução livre nossa.
}

Texto Digital, Florianópolis, v. 9, n. 2, p. 230-258, jul./dez 2013. ANO. ISSNe: 1807-9288 
estabelecem os padrões veem de forma distorcida e afastada da realidade; impõem regras de conduta baseadas nas observações que têm; são obedecidos, pois são os que têm o poder; e distorcem a realidade observada pelo homem comum. Esse comportamento arrogante é característico do cientista, também. Ele é o senhor da realidade; qualquer indivíduo que veja diferente é recomendado a usar óculos que distorçam sua visão tanto e na mesma direção da visão da ciência. Como poderemos saber quais são as formas geométricas utilizadas por seres de outros planetas? O que é música para um marciano, pode ser ruído para nós.

Outra forma de arrogância denunciada por Swift em seu livro é a extrema dificuldade encontrada pelos homens da ciência para ouvir. Eles estão sempre falando sobre suas pesquisas ou raciocinando sobre elas. Como a população de Laputa é formada, quase cem por cento, de cientistas (matemáticos e astrônomos), eles sempre trazem consigo um serviçal com uma vareta para indicar de quem é a vez de falar (tocando com a vareta na boca do falante da vez) e para quem ele está endereçando seu discurso (toca o ouvido do destinatário), este, portanto, tem que prestar atenção ao falante. Para concluir sobre $o$ assunto da arrogância, observem o que Gulliver nos diz sobre a população da ilha: "They are very bad reasoners, and vehemently given to opposition, unless when they happen to be of the right opinion, which is seldon their case" (p. 131) ${ }^{9}$. Qual de nós já não assistiu a cenas de discussões acirradas entre cientistas, cada um negando integralmente a posição do outro? Ou que, ouvindo seu interlocutor definir um fenômeno correta e coerentemente, nega a conceituação para, depois, parafraseando-o, dizer exatamente a mesma coisa. Nega a definição correta do outro, só para contrapor e ter direito à voz, embora dizendo rigorosamente a mesma coisa. Desta forma, é difícil existir concordância. Eles estão sempre em campos opostos e sozinhos no que fazem. Outro traço de arrogância denunciado por Swift é o estranho costume de eles darem opiniões sobre assuntos nos quais não têm conhecimento profundo. Gulliver constata que os cientistas estão,

\footnotetext{
${ }^{9}$ [Eles são maus raciocinadores e, veementemente, dados à oposição, a não ser que aconteça de estarem com a opinião certa, o que é um caso raro.] Tradução livre nossa.
} 
permanentemente, se intrometendo em assuntos de Estado e apaixonadamente disputando cada centímetro da opinião pública (p. 130).

Voltando para o aspecto do nome do local - Laputa; do seu relacionamento com dinheiro, e concluir o raciocínio que iniciamos quanto às disputas por investimentos em projetos de pesquisa. Argumentávamos que as áreas de conhecimento começaram a se afastar na medida em que as fontes de financiamento minguavam. Ainda questionamos que para poder competir pelos favores dos mecenas mercantilistas, os cientistas começaram a prometer resultados mais imediatos, barateando seus projetos. Com isso, ao invés de darem toda a atenção ao seu objeto de estudo e às relações possíveis com outras áreas de conhecimento e possíveis alargamentos do projeto, eles passaram a enfocar o objeto como uma coisa completamente isolada e trabalharem, exclusivamente, para conseguir o intento inicial, deixando de lado todas as riquezas novas; grandes e pequenas descobertas que a pesquisa maior traz atrelada a si mesma. Em sua visita a Lagado, uma metrópole do reino de Laputa, Gulliver tem a oportunidade de visitar a grande Academia de Ciências de Lagado (uma menção satírica frontal a Royal Society of Science) e conhecer projetos fascinantes - insistimos que os projetos descritos por Gulliver foram extraídos pelo seu criador dos anais da Real Academia de Ciência, subtraindo algumas cores características da ficção - como o de transformar fezes nos alimentos que foram consumidos por quem as excretou; guardar raios de sol em legumes para serem utilizados quando o sol mostrasse seus primeiros sinais de fraqueza; uma máquina de pensar constituída de vários dados de seis faces e, em cada face, escrito uma palavra no idioma local, onde os dados eram impulsionados por tiras de borracha e, a cada lance, um grupo de auxiliares escrevia as frases formadas - já existiam dezenas de livros com as frases anotadas para depois serem organizadas - acreditava o cientista encarregado do projeto que, dessa forma, eles teriam a história do mundo recontada da maneira correta; outro pesquisa era de um médico que tratava de cólicas introduzindo gazes dentro do intestino pelo ânus do enfermo, ele acreditava que agindo de modo reverso ao que queria a natureza, ele podia tratar todas as doenças - Gulliver estava com cólicas e por 
isso foi apresentado ao médico, mas quando soube que tinha de introduzir uma cânula de $24 \mathrm{~cm}$ em seu ânus, desistiu do tratamento. Esses são apenas alguns dos muitos projetos visitados pelo viajante.

Gulliver faz interessantes constatações sobre a parte pecuniária à medida que passeia pela Academia. Já em sua primeira visita, ele nos informa do primeiro acesso por dinheiro por parte do cientista: "[...] and (he) entreated me to give him something as an encouragement to ingenuity" $(145)^{10}$. Ao que Gulliver completa:" I made him a small present for my Lord had furnished me with money on purpose, because he knew their practice of begging from all who go to see them." ( $p$. $145)^{11}$

É clara a importância do dinheiro para os pesquisadores. No caso acima relatado, observamos um assalto direto de um cientista sobre um cidadão que, supõe-se, já contribui para aquela pesquisa pagando seus impostos. Mas não causa espanto tal prática, quantas vezes visitamos projetos que ao final do tour nos solicitam ajuda para incrementar o projeto? Ou mesmo vendem bugigangas com nome do local explicando que o lucro será revertido para a pesquisa em andamento? Estas são práticas que nasceram com o inocente mercantilismo renascentista. Neste determinado momento da história, os estudiosos passaram a ter de, paralelamente ao seu trabalho primeiro, correr atrás de financiadores que bancassem os custos da pesquisa. E, sem sombra de dúvida, dado a aspectos socioeconômicos, que já mencionamos, ficou mais fácil amealhar as verbas para projetos executáveis e utilizáveis num átimo, do que trabalhar com ideias humanísticas de entremeios mais longos. Entra em voga uma perversa lógica utilitarista que campeia em nossas academias e na sociedade até hoje.

Swift denuncia outra prática extremamente conhecida para nós, brasileiros, e possivelmente em dezenas de outros países. Outro tipo de abordagem praticada

\footnotetext{
${ }^{10}$ [Ele me solicitou que lhe desse alguma coisa como encorajamento à genialidade.] Tradução livre nossa.

${ }^{11}$ [Eu lhe dei um pequeno presente, pois meu Lorde tinha me fornecido dinheiro de propósito porque ele sabia a pratica deles pedirem algo a todos que os visitavam.] Tradução livre nossa.
} 
por essa nova estirpe de cientistas que é, também, um assalto, sendo que, dessa forma, com a bênção do estado: o pesquisador que inventara a máquina de pensar reclama de poucos funcionários e apenas um equipamento e sugere que poderia avançar mais

[...] if the public would raise a fund for making and employing five hundred such frames in Lagado, and oblige the managers to contribute in common their several collections.(p. 150) ${ }^{12}$

Nós já assistimos à criação de quantos Fundos? Neste momento em que escrevemos, ouvimos na televisão notícias da criação do Fundo para Ciência e Tecnologia nos mesmos moldes do Fundo para o Petróleo (Isto foi em 2002). Difícil é fazer os governantes contribuírem igualmente a todos os cidadãos. Vimos, no exemplo, como o estado passa a fazer o papel de arrecadador toda vez que a pesquisa é interessante para o seus governantes e, também, como forma de centralizar mais poder, uma vez que só serão financiados projetos de interesses dos controladores dos fundos ou projetos propostos por amigos dos gerenciadores da verba.

No estágio atual, essas coletas de dinheiro, sejam diretamente entre cientista e cidadão ou, indiretamente com o estado intermediando, são práticas reinantes e já não causa rubor falar sobre elas. Interessante é a forma que Swift usou para registrar a prática nos seus dias: uma sátira tosca para denunciar uma sordície descabida.

Uma outra passagem que merece citação $^{13}$ por sua atualidade, ainda sobre 0 assunto de como financiar pesquisas, encontramos na página 154, 1ำ parágrafo. Dois acadêmicos discutiam acaloradamente sobre formas mais efetivas e cômodas de conseguir dinheiro. O primeiro advogava que deveria ser estabelecida uma taxa sobre os vícios e os crimes: a soma deveria ser dividida da maneira mais justa entre os cidadãos para ser paga como imposto; o segundo

\footnotetext{
${ }^{12}$ [Se o público levantasse um fundo para fazer e utilizar quinhentas estruturas daquelas e obrigar os administradores a contribuir como suas várias fontes de receita.] Tradução livre nossa.

${ }^{13}$ Existe um outro assalto por dinheiro descrito na página 172 , fim do $3^{\circ}$ parágrafo mas, por questão de espaço, evitamos a citação.
} 
era frontalmente contrário à ideia e propunha que deveria ser cobrada uma taxa sobre os valores do corpo e da mente que cada pessoa acreditava ter. A taxa mais alta seria pelo grau de interesse que o sexo oposto tivesse pela pessoa e deveria ser medido pelo número de parceiros que cada um tenha tido. No entanto, sabedoria e conhecimento deveriam ser isentos; nenhum homem deveria reconhecer nele mesmo essas qualidades.

Obviamente, Swift brinca com as ideias estapafúrdias que as pessoas têm em relação a si mesmo dentro da sociedade. Mas também denuncia a criatividade que acomete pesquisadores quando o assunto é dinheiro.

São dessas passagens que acreditamos poder propor uma etimologia para o título do capítulo em Gulliver's travels. Laputa representando a puta, como é quase unanimidade entre pesquisadores de Swith e seus textos; indica um caminho de leitura plenamente confirmado pelas passagens citadas e outras de menor relevância, mas no mesmo sentido, que encontramos no texto. Nas passagens citadas e nas omitidas existe sempre um professor, pesquisador, estudioso das ciências envolvido na trama. São esses senhores que solicitam dinheiro ou que idealizam maneiras de conseguir verba para suas pesquisas. São esses senhores que cedem um dom raro que thes foi dado, a genialidade, como o sexo da prostituta, em troca de dinheiro. Um raio-X para obtermos o blueprint do texto revelaria que três palavras - e suas derivadas - permeiam cada parágrafo, elas seriam: dinheiro, ciências e poder. O que diremos agora pode ruborizar um leitor mais pudico, mas, o que nos parece claro é que Swift estava colocando o cientista como protagonista do capítulo chamado Voyage to Laputa, com todas as ligações que se possa fazer, em especial quando observamos que é sempre um cientista que está solicitando - ou planejando como solicitar dinheiro em troca de seus serviços profissionais.

O fato de o estudioso ter de levantar fundos para sua pesquisa e suas consequências imediatas, já listadas, levaram, acreditamos, os ramos de conhecimento a entrarem em processo contínuo e irreversível de afastamento 
entre eles. Mesmo dentro de uma mesma área, os pesquisadores se atritam e amesquinham seus relacionamentos. Biólogos não se entendem com químicos, que não se entendem com físicos, que não se entendem com biólogos - o ciclo é muito maior. Se entre cientistas das chamadas ciências duras não há possibilidade de entendimento, seria um exercício sádico pensar nas relações deles com os das humanidades.

Voltemos ao século XVIII só para imaginar que tipo de pesquisa estudiosos da área das, hoje ditas, ciências humanas poderiam oferecer aos mercadores que trouxesse para estes resultados rentáveis, aplicáveis rapidamente. Mesmo hoje, em pleno século XXI, se analisarmos friamente, percebemos que os financiadores olham com desdém para projetos humanísticos. Em uma análise fria, como propomos, aos olhos do cientista duro, os estudos humanísticos atrasam mais do que ajudam o desenvolvimento das ciências. Vivemos num mundo que perdeu seu norte! A ciência, definitivamente, não é voltada para o bem-estar do homem, mas para o enriquecimento de uns e a vaidade de outros.

O ficcionista Michael Crichton, popularizado pelos seus romances $O$ enigma de Andrômeda e Mundo perdido, faz um balanço muito sereno das tecnologias disponibilizadas para as ciências e para as humanidades e as diferenças dramáticas no desenvolvimento de cada área graças ao desequilíbrio insano na distribuição de investimentos. É através do personagem Bob Doniger, (na estória um físico quântico de primeira linha e absurdamente arrogante e ambicioso) que habita o romance Linha do tempo. Ele propõe:

\footnotetext{
- Vamos examinar por um instante [...] a desigualdade com que a tecnologia influenciou os diversos campos de conhecimento no século $X X$. A física emprega as tecnologias mais avançadas, incluindo aceleradores com vários quilômetros de diâmetro. A mesma coisa ocorre na química e na biologia. Há cem anos, o Faraday e o Maxwell possuíam laboratórios particulares minúsculos. O Darwin trabalhava com um caderno e um microscópio. [...] Mas as ciências humanas? Durante esse período, o que aconteceu com elas? [...] A resposta é nada. Não houve nenhum avanço tecnológico significativo. O estudioso de literatura ou de história trabalha hoje exatamente como seus antecessores de cem anos atrás.(2000, p.167-168)
} 
Contextualizando: Doniger é um físico excepcional que conseguiu se livrar de seus financiadores e passou, ele mesmo, a fazer o papel do financiador de outros estudiosos. Tem uma empresa de pesquisa física muito lucrativa e financia um grande projeto de arqueologia "desinteressadamente". Na passagem em tela, ele tenta convencer um grupo formado por arqueólogos a empreender uma viagem fantástica utilizando uma máquina experimental. Um dos seus argumentos de convencimento é que ele desenvolve aquele projeto com o fim exclusivo de dotar áreas como a história, arquitetura e arqueologia de um meio de pesquisa condizente, comparativamente, com os meios utilizados pelas ciências duras. Obviamente, Doniger está mentindo descaradamente. O invento seria de fato utilíssimo para as disciplinas citadas, mas o fim planejado passa longe de projetos acadêmicos.

A ruptura existe. Imaginar o que aconteceu, após a ruptura, nas relações entre ciência e arte, é falar não mais de uma fenda, mas de um cânion de profundeza abissal. A arte, no mundo de visão tacanha que descrevo, só tem valor enquanto commodity, isso, bem dito, as artes plásticas. Raríssimos são os artistas que conseguem algum tipo de incentivo para produzir seus trabalhos. O mais comum em nossos dias é o artista dedicar algumas horas para a produção de suas obras e, no tempo restante, comercializar um pouco de sua capacidade de criação, trabalhando para fins comerciais.

Mas, dentro de multidões de artistas, sempre, uns poucos, conseguem sobressair e viver do que produzem artisticamente. Não existe qualquer interesse institucional para o financiamento de projetos artísticos. Mesmo porque, toda arte é subversiva, mesmo quando não é produzida com esse intuito. As peças de arte dialogam com os que tomam conhecimento de sua existência e a mensagem deixada por esse diálogo vai depender do momento histórico e do estado emocional na vida do indivíduo. É algo sobre o qual não se tem controle, não se pode saber que tipo de reação uma música, um quadro ou um poema terá sobre os indivíduos. Existem histórias fantásticas de efeitos inesperados que peças artísticas tiveram sobre os indivíduos ou sociedade: é famosa uma onda de 
suicídio na Alemanha após a publicação do romance Werther, de Goethe; as violentas reações do jovens após a leitura de Les confessions, de Rousseau; mais recentemente, os tumultos urbanos que levaram à queda de ministros na Colômbia após a publicação, em jornais, de uma série de crônicas por Gabriel García Márquez, que depois foram colecionadas em um livro intitulado Relato de um náufrago; ou, o mal-estar causado pelo Guernica de Picasso, este só pôde ir para a Espanha no final da década de 90 do século passado. São completamente alheias aos desejos dos autores as reações à leitura da obra de arte depois de tornada pública. Se constatamos que, no capítulo de Swift explorado acima, uma das palavras-chave no processo de financiamento de projetos é poder, e que poder depende de controle, para o Ser (fa)logocêntrico que povoa nosso mundo, as obras de arte são objetos nefastos, dignas da mais ardente fogueira inquisitória ou nazista para aqueles que têm o poder. Para eles, nem obras de arte lisonjeiras devem ser incentivadas, pois, como dito, não existe como controlar as reações populares a elas. No máximo, as obras de arte são valorizadas como commodity, para os poderosos financiadores.

Dessa forma, os gênios da antiguidade que consideravam o universo e o homem como seu objeto de estudo, não interessando por quais caminhos iriam abordálos, transformam-se, na modernidade, em um estudante, de visão atrofiada, que no começo de sua vida adulta tem que se decidir como ele verá o mundo profissionalmente, se de um laboratório repleto de pipetas, beckers e máquinas sofisticadas ou se desenhando, pintando, esculpindo ou escrevendo. De antemão, ele sabe que optando pelo laboratório e não ferindo nenhuma regra básica de conduta para os cientistas ele terá, pelo menos, sua sobrevivência garantida, podendo, com um golpe de sorte, tornar-se um astro das ciências. O outro caminho, o do artista, leva-o por uma estrada sinuosa de onde não se pode vislumbrar o futuro.

Discutidas as relações entre ciências, humanidades e arte, da forma que as percebemos, passamos a um breve exercício para apontarmos algumas peculiaridades quando pensamos nas relações entre ciência e literatura. 
Das relações já comentadas, a situação da arte (embora a literatura seja arte, pretendemos tecer alguns comentários mais específicos sobre as condições dela frente à ciência e aos cientistas) é a que mais se aproxima da literatura, sendo que consideramos que esta tem peculiaridades próprias. Já frisamos que as artes plásticas - uso esse termo para me referir, especificamente, à pintura e à escultura - têm um valor mercadológico que faz alguma diferença das outras (quando pensamos em fontes de financiamento). Qualquer capitalista tem interesse de ter uma escultura de Brennand, por exemplo, nos jardins de seu escritório. Mesmo que ele não goste das formas fálicas do artista. Com isso, ele dá sinal de prosperidade a todos que visitam o seu prédio. A arte ganha uma funcionalidade esquisita, definindo o status daquele que ali habita. Embora isso, hoje, seja uma prática corriqueira, não é exclusividade de nossa época. Existe também um mercado de arte como existe o de ações de empresas. Quadro de grandes mestres valem milhões (seriam as ações blue chips) e marchands investem em artistas jovens (ações secundárias, de grande risco, mas de rentabilidade altíssima, quando realizadas), pensando em lucros em um futuro a médio ou longo prazo.

A literatura, mercadologicamente falando, aparenta-se mais com as artes cênicas - seria sua prima pobre. Tanto nas artes cênicas quanto na literatura encontramos dois filões bem distintos. Um muito rico e, portanto, abundante, popular e, outro, muito pobre, também volumoso, mas desconhecido. Nas artes cênicas, a poderosa indústria fílmica hollywoodiana ${ }^{14}$ e o main stream do teatro estão no lado rico e não necessitam de nossa apresentação. Os correspondentes na literatura seriam os grandes grupos editoriais interessados na publicação de best-sellers. Esses institutos têm suas ramificações em cada parte do mundo e o esquema de financiamento segue, mais ou menos, o mesmo padrão em todo lugar. Dessa forma, a boa literatura, o bom teatro ou o bom filme se ressentem com o desinteresse dos patrocinadores.

\footnotetext{
${ }^{14}$ Publicamos um ensaio sobre o assunto intitulado Uma reflexão sobre cinema e literatura, na publicação eletrônica da UBE/Brasília Usina de Letras em http://usinadeletras.com.br.
} 
Como já dissemos, a disputa por financiadores distanciou as áreas de conhecimento. Isso levou cientistas e artistas a cultivarem um desprezo mútuo que terminou por refletir na produção do artista e na qualidade de vida e do trabalho do cientista. O primeiro, devido ao antagonismo tenaz, passou a evitar falar sobre ciência e quando o fazia era para ridicularizá-la, já vimos o caso de Swift. O cientista, dentro da mesma perspectiva repulsiva, deixou de frequentar a arte, o que, com o passar do tempo, faz com que ele perca o norte orientador das ações humanas. Essa falta de interação trouxe perdas e danos irreparáveis.

Defenderemos que a real busca pela verdade acontece no local de simbiose entre os ramos do conhecimento o qual chamamos botão umbilical do conhecimento. As descobertas da ciência geram um signo, ou uma série de signos, que é rapidamente aprendido e refletido pelas artes em forma de metáfora. Essas metáforas têm um grau de pureza e dificuldade que, geralmente, não são compreendidas pelo homem comum, só após muito tempo a riqueza das metáforas vai se esvaindo pela difusão do novo conhecimento, e então o homem é capaz de entendê-las. Neste momento ela transforma a realidade e o cientista sente-se atraído pelo novo panorama e passa a buscar signos que expliquem a nova realidade. Isso ocorre, não em uma rota cíclica, mas num espiral permanente, onde a trajetória da busca diminui de diâmetro a cada descoberta e a cada metáfora, fazendo com que cada vez mais o intervalo de tempo entre grandes descobertas diminua até chegar o dia da revelação total. $O$ ambiente hostil de hoje faz com que a pesquisa do cientista tenha sua direção desviada e faz com que o poeta metaforize sobre um vácuo. O primeiro aponta para um conhecimento artificial alheio aos propósitos do homem. E o segundo vaga em abstrações, por se negar a reconhecer como natural a verdade apontada pela ciência.

Essa troca entre literatura e ciência, que num passado distante era tão constante, chegou, acreditamos, à cota zero, nos cem anos que vão do fim do primeiro quarto do século XIX até o fim do primeiro quarto do século XX. Em uma 
publicação de 1926, encontramos um teórico e crítico literário de então, afirmar que

\begin{abstract}
Since poetry and science are now supposed to be antithetical and mutually exclusive, it has been difficult to conceive that one of the major English poets [Geoffrey Chaucer] ever exercised his mind to any remarkable extent in the realm of scientific theory and abstraction; and that he should have been impressed to the point of taking seriously - at least to artistic purpose - these monstrosities of error, now seems almost unbelievable. Yet such appears to have been the case. (Curry, 1960, p. $(X)^{15}$
\end{abstract}

Pela citação, observamos que em pleno século $X X$, pratica-se uma intolerância cega entre a ciência e a poesia. A intransigência denunciada por Walter Curry soa como uma rixa pessoal; uma repulsa visceral. O crítico assume uma postura tão agressiva aparentando ter esquecido que quinhentos anos o separam de mundo de Chaucer, não lhe cabendo portanto o direito de emitir um juízo de valor tão agressivo sobre a ciência medieval ou sobre a poesia Chauceana. Esqueceu o crítico que, diante de um evento, ou conjunto de eventos ocorridos com tamanha distância temporal, ele deveria ser analisado dentro da cultura em que está mergulhado ou comparativamente com o que ocorre ou ocorreu em outra época, mas não exigir um sincronismo absoluto entre seu mundo e o medieval, principalmente quando a prática artística em tela costuma ser considerada das melhores já exercidas em língua inglesa. Mesmo com esse ataque já no início da introdução do seu livro, Curry faz um belíssima análise da poesia de Chaucer e mostra como o poeta usou conhecimentos de fisiognomonia, gemologia, astronomia, alquimia, medicina (importante estudo dos quatro fluidos que constituem a personalidade do homem), medicina astrológica, astrologia, especialmente para construir seus personagens. Embora o crítico ataque o poeta por ter feito uso de conhecimento tão bárbaros em sua dicção ele, mais adiante, ainda na introdução de seu livro, lamenta que ninguém tenha dado importância à

\footnotetext{
${ }^{15}$ [Desde que poesia e ciência são, agora, supostamente, antitéticos e mutuamente excludentes, é difícil conceber que um dos maiores poetas ingleses tenha exercitado sua mente, em qualquer grau de extensão, no mundo da teoria e abstração científica; e que ele tenha se impressionado ao ponto de levar a sério - pelo menos com propósitos artísticos - essas monstruosidades de erros, apresenta-se, agora, quase inacreditável. Embora esse pareça ser o caso.] Tradução livre nossa.
}

Texto Digital, Florianópolis, v. 9, n. 2, p. 230-258, jul./dez 2013. ANO. ISSNe: 1807-9288 
ciência medieval como mais uma ferramenta para entender melhor aquele mundo e a poesia que era feita então ( $p$. xix), e continua para reconhecer que

[...]Assuming presumably - being touched by the arrogance of the modern scientific spirit - that a revial of erroneous beliefs of a dark age could be of no service in the interpretation of a literary artist of that time [...]. The medieval sciences, however ludicrously inadequate they now seem to have been, were doubtless as significant to the people of the fourteenth century as accepted principles of to-day are to us. (Curry, $1960)^{16}$

A impressão que se tem após a leitura de dois trechos tão antitéticos (para usar o termo do autor) dentro de uma mesma introdução, mas a finalidade única do primeiro, que aparece já no início do capítulo, é, exclusivamente, chamar a atenção do leitor, prender o leitor já na primeira página. Uma declaração bombástica faz com que o leitor fique curioso com o que mais vai ser dito. Mas, próximo do fim da introdução, o autor se redime fazendo uma ponderação equilibrada e respeitosa sobre os assuntos que guiarão seu trabalho de investigação. Entre perdas e ganhos, Curry faz um levantamento cuidadoso das ciências na sociedade medieval e uma bem conduzida e clara demonstração de como o conhecimento dos princípios científicos da época influenciaram Chaucer na criação de seus personagens e seus enredos.

Outro crédito que o autor merece é pela coragem de, numa época em que os ânimos entre poetas e cientistas estavam tão acirrados, publicar um livro (que já teve diversas edições, tal é sua importância) com uma tese que aproxima um dos mais festejados poetas ingleses com a ciência de sua época. Esse passo, junto com outros, como uma edição da PMLA ${ }^{17}$ dedicada a textos tratando das relações entre Chaucer e as ciências medievais, abrem novas perspectivas para o relacionamento entre as áreas e o antagonismo aos poucos vai esfriando.

\footnotetext{
${ }^{16}$ [...] assumindo, presumivelmente - tocada pela arrogância do espírito científico moderno - que a recordação de crenças erradas da idade negra não seria de qualquer utilidade na interpretação de um escritor daquele tempo ... As ciências medievais, embora risivelmente inadequadas, parecem ter sido, sem dúvida, tão significantes para o povo do século quatorze quanto os princípios de hoje são para nós.] Tradução livre nossa.

${ }^{17}$ PMLA - Publications of the Modern Language Association of America, XXXIX, 1924.
} 
Cientistas e artistas entendem que a luta pelo financiamento que, aparentemente, gerou a separação entre eles, não é motivo para eles não se visitarem intelectualmente. Tem-se, hoje, uma visão mais clara do joguete que ambas as partes coadjuvaram para desfrute de uma classe dominante que tinha, e tem, o total juízo e o poder sobre as pesquisas que deveriam, ou não, serem financiadas. Os atores secundários (pesquisadores, escritores) reconhecem a importância de seus pares de outras áreas e, alguns, mais esclarecidos, sabem que não podem caminhar sem o outro. Mas sabem, também, que disputas e ofensas que duraram séculos não podem ser curadas em uns poucos anos.

Apesar das publicações citadas acima, uma em 1924 e outra em 1926, não se pode dizer que a partir daí as relações entre as áreas sofreram qualquer modificação generosa. Talvez o grande abismo entre as áreas tenha virado abismos glaciais. Cada lado continuou seu trabalho da melhor maneira possível dentro do cenário que se apresentava. As disputas por financiamento continuaram, com o lado da arte, Humanidades, como sempre, levando a pior, mas já dormente às injustiças. Pelo menos, pouco se atacavam mutuamente. Até aparecer um certo C. P. Snow.

Snow começou sua vida profissional como cientista, um químico. Ainda muito jovem, ele provocou um Schandenfreude ${ }^{18}$ com a publicação mal fundamentada da descoberta de uma maneira artificial de produzir vitamina A. Cometeu um erro que não é perdoado na comunidade científica e com isso foi alijado dela sem maiores condescendências. Sendo de origem humilde e sabendo que sua vida como pesquisador se encerrara, buscou outra maneira de sobreviver: virou ficcionista. Talvez tenha feito mais sucesso como escritor do que faria dedicando sua vida inteira à ciência. Durante a Segunda Grande Guerra foi convocado para um posto civil com a incumbência de treinar físicos para a indústria bélica inglesa. Posto que ocupou durante os diversos anos da guerra e o introduziu na vida política da Inglaterra, chegando, inclusive, ao cargo de ministro.

\footnotetext{
${ }^{18}$ Termo usado pela comunidade científica para a situação em que um de seus pares divulga o resultado de uma pesquisa que não pode ser reproduzida pelos outros e é considerada como errada ou fraudulenta. O termo significa algo como "sentir um prazer malicioso ou sádico".
}

Texto Digital, Florianópolis, v. 9, n. 2, p. 230-258, jul./dez 2013. ANO. ISSNe: 1807-9288 
Quando foi convidado para conferir a Rede Lecture, de 1959, escolheu como tema literatura e ciência - teve o título de The two cultures ${ }^{19}$. Tratou do assunto como um experto; considerava-se conhecedor das duas áreas, pela sua formação e profissão e do abismo existente entre os dois grupos de intelectuais. Esperavase que com ele, por se tratar de uma pessoa que pertencia, simultaneamente, aos dois mundos e ser uma pessoa cujas características de personalidade aliava polidez e intelecto, começasse a amenizar as rixas históricas (Blake versus Newton - Blake debatia com o que ele chamava de "legado de Newton"; Coleridge versus Benthan; Huxley versus Arnold e outros de menor importância) sobre o assunto. Engano! $O$ discurso de Snow foi um dos ataques mais virulentos lançado sobre a literatura em todas as épocas. Um discurso vil em que o orador não se conteve em criticar a produção de poetas, mas criticou posições pessoais privadas de escritores e poetas. Os ataques e denúncias variavam dentro de um amplo espectro que ia de opções políticas, religiosas e sexuais. Não fez tais denúncias de forma genérica, fez questão de nomear quem era aficionado a esta ou aquela prática. A fala tem partes valiosas, sem dúvida. Snow faz um levantamento preciso das relações entre os mundos, mas peca pelo excessivo apego à ciência e tecnologia. Ele transmite a ideia que a literatura tem que se adaptar para atender as necessidades de uma sociedade dominada pela ciência e pela tecnologia. Ou seja, deixa a impressão de que a cultura é a ciência, e a literatura, por fazer parte desse sistema, tem que validar sua existência corroborando e colaborando para o pleno desenvolvimento e entendimento da ciência.

É óbvio que uma ação insultuosa dessa natureza não ficaria sem resposta e, em 1962, em uma palestra na mesma Cambridge, F. R. Leavis retribuiu os insultos de Snow no mesmo nível. Hoje, essa disputa é conhecida como a Leavis-Snow controversy. O discurso de Snow, que se pensava colocar um fim em uma série de disputas, terminou, ele mesmo, gerando uma nova.

\footnotetext{
${ }^{19}$ Virou livro publicado pela Cambridge University Press: Cambridge, 1995. Esta edição tem uma excelente introdução por Stefan Collini.
}

Texto Digital, Florianópolis, v. 9, n. 2, p. 230-258, jul./dez 2013. ANO. ISSNe: 1807-9288 
Existe algo de muito positivo nesta disputa: em ambas as partes, pessoas começaram a verificar que a contenda tinha fugido, definitivamente, dos limites dos debates acadêmicos/científicos aceitos pelas comunidades envolvidas. Era preciso repensar a situação, urgia retornar as relações para um nível de cordialidade previsível para seres humanos. Ao mesmo tempo, apareciam nas universidades inglesas e americanas disciplinas novas que, com o passar dos tempos, cumpririam o papel de espaço neutro em que cientistas e humanistas pudessem dialogar, elas eram: a história da ciência e da filosofia da ciência. Esses embriões pacificadores cresceram; são disciplinas das mais respeitadas por humanistas e cientistas e já apresentam uma nova geração de disciplinas que vem para nos ajudar e pensar melhor o que queremos para o nosso futuro. São exemplos delas: ética e ciência; arqueologia e ciência; antropologia e ciência e literatura e ciência.

Em 1985, durante XVII Congresso Internacional de História da Ciência, foi inaugurada a Society for Literature and Science (posteriormente foi acrescentado o temo and the Art). A sociedade cresceu em passos muito largos e tem sócios em quase todos os países do mundo. Realiza um congresso anualmente com centenas de participantes das mais diversas áreas de conhecimento. Publica uma revista especializada chamada Configurations, pela prestigiosa Johns Hopkings University Press e indexada pelos mais exigentes institutos. Além da revista, a Sociedade publica um boletim quatro vezes por ano e suporta a publicação de uma série de livros sobre ciência e literatura. Também cumpre o papel de índice, publicando anualmente os títulos pertinentes à área. Evidenciamos nessa bibliografia um fenômeno interessante: o crescente número de títulos publicados a cada ano sobre as relações entre ciência e literatura - a lista de 1999 supera 1200 títulos publicados em um ano nos EUA (A indexação aconteceu até 2004, no momento, a listagem existe, mas cabe a cada autor indexar seu trabalho na lista).

A escassez de publicações anteriores (por séculos), a riqueza do material existente para ser analisado, a diversidade de abordagens possíveis são alguns 
dos motivos que esses estudos têm atraído tantos pesquisadores para trabalharem na área. Existe, ainda, muita confusão no trato do objeto de pesquisa. A começar pelas relações existentes, como: o contraponto da ciência não é a literatura e sim a teoria literária; a literatura é o par do objeto de pesquisa do cientista, seja ele o que for; a literatura não pretende ser uma ciência nos moldes conceituais, desta, aceitos atualmente - não se pode exigir que o fenômeno estético na literatura seja replicado por qualquer leitor, muitíssimo pelo contrário; começa-se a aceitar que o discurso das duas áreas têm estratégias similares - são fortes os estudos de análise do discurso científico por nãocientistas, especialmente comparatistas.

Existem ainda muitas barreiras a serem superadas, mas existem, também, e cada dia mais, tentativas honestas de aproximação. No Brasil, o Instituto Itaú Cultural junto com a revista Leonardo promovem, a cada ano, encontro de cientistas e poetas. No ano de 2000, a concentração foi nos envolvimentos entre poesia e novas tecnologias, inclusive com debates à distância. A UFRJ mantém um seminário permanente sobre as relações entre ciência e literatura; mensalmente um convidado palestra sobre um tema e abre-se um debate no local, que depois continua eletronicamente (eventos de 2002).

Ainda existem ranços entre as partes, mas não vemos mais agressões ${ }^{20}$ e quando ocorrem nota-se que são ações isoladas. A discrepância de números no que diz respeito e financiamento só faz crescer. Cada dia, menos se investisse em literatura, em arte ou nas humanidades, mas parece que os humanistas estão descobrindo outras maneiras de conseguir recursos, estão aprendendo a jogar o jogo de outra maneira e, paulatinamente, estão modificando o panorama. Mas deve-se acrescentar que a sociedade começa a sair de uma fase onírica em que sonhava que a ciência era a resposta para todas as mazelas. Ela acorda

\footnotetext{
${ }^{20} \mathrm{Na}$ medida em que estou revisando este texto que foi escrito em 2002, não posso deixar de mencionar algumas investidas recentes contra a busca por um ambiente pacífico entre as áreas: ao criar o Programa Ciência sem Fronteira, o governo brasileiro excluiu do Programa toda a área de Humanidades, Sociológicas e Artes; e, a lista de prioridades das agências de fomento brasileiras que colocam as Humanidades e Artes como as que devem receber os menores recursos e bolsas.
} 
querendo conhecer a si própria, querendo tomar as rédeas de seu destino. Percebe que a ciência, como a política, se não for bem entendida e vigiada pode se tornar um pesadelo com final trágico. Nesse novo ambiente, as artes ganham um novo status, o homem volta a perceber que é através delas que pode melhor definir sua própria fisionomia, para, então, escolher o seu caminho.

\section{THE TWO CULTURE - AGAIN}

ABSTRACT: This work paper has the purpose of casting some light on the stage in which we find the relationship between the hard sciences (physics, chemistry, biology), the arts and the literature, or better, between scientists and artists. It shows that in the past there was no separation and points to some factors that led to the distance we find today.

KEYWORDS: C. P. Snow, Swift, Area Division, Scientists and Artist,. Research Funding.

\section{REFERÊNCIAS}

BACON, Francis. The advancement of learning e The New Atlantis. In: JOHNSTON, Arthur (Ed.). The advancement of learning and The New Atlantis. London: Oxford University Press, 1974.

BRANDÃO, Saulo. Uma reflexão sobre cinema e literatura. Disponível em: $<$ http://usinadeletras.com.br/exibelotexto.phtml?cod=149\&cat=Ensaios $>$.

CRICHTON, Michael. Linha do tempo. Rio de Janeiro: Rocco, 2000.

CURRY, Walter Clyde. Chaucer and the medieval sciences. New York: Barnes and Noble, 1960.

DAVIES, Paul. Is the universe a machine? In: HALL, Nina (Ed.). Exploring chaos. A guide to the new science of disorder. New York and London: NortBooks, 1993.

EINSTEIN, Albert. Ideas and opinions. New York, Crown, 1954.

FOUCAULT, Michel. The archeology of knowledge. London: Routledge, 1994.

FOX, Christopher (Ed.). Gulliver's travels: A case study in contemporary criticism. New York: Bedford Books, 1995.

GLEICK, James. Chaos: Making a new science. New York: Viking, 1987.

HENRY, John. A revolução científica e as origens da ciência moderna. Rio de Janeiro, Jorge Zahar, 1998.

HUSXLEY, Aldous. Literature and science. New York: Harper and Row, 1963. 
IRSIZ, Gurol; GRUMBERG, Teo. Carnap and Kuhn: Arch enemies or close allies? British Journal for the Philosophy of Science. v. 46, n. 3, p. 136-145, 1995.

JAMESON, Fredric. O pós-modernismo e a sociedade de consumo. In: KAPLAN, E. Ann (Org.). $O$ mal-estar do pós-modernismo. Rio de Janeiro: Jorge Zahar, 1994.

JOHNSTON, lan. Jonathan Swift's Voyage to Laputa. Disponível em: $<$ http://malvm1.mala.bc.ca/ mcneil/lec/lecswift lap.html>.

KHUN, Thomas. The structure of scientific revolutions. Chicago: University of Chicago Press, 1970.

SNOW, C. P. The two cultures and the scientific revolution. New York: Cambridge University Press, 1960.

SWIFT, Jonathan. Gulliver's travels. In: LANDA, Louis A. (Ed.). Gulliver's travels and other writings by Jonathan Swift. Cambridge: The Riverside Press, 1960.

Texto recebido em 30/11/2013.

Texto aprovado em 05/12/2013. 